\title{
A saga of the Thames
}

\author{
Eric Ashby
}

IN 1778 Joseph Bramah took out a patent for a device which has been the cause of death for multitudes of people. It was not a weapon of war: it was the water closet. By the early nineteenth century it became the aspiration, and then the expectation, of householders in towns to have running water and a water closet.

In their enthusiasm they overlooked a simple and grave consequence. Water companies - there were seven of them in London in the year 1800 - brought water into some 100,000 homes, but there were no arrangements for taking the water out again. In 1800 it was forbidden to discharge domestic waste into the London sewers; their purpose was to collect run-off from the streets. Cesspools became flooded, soil workers could no longer empty them, there was a persistent stench round the most respectable homes. So in 1815 permission was given for the wastes to be discharged into sewers and thence into the Thames. These wastes, together with phenols and ammonia from the Gas Light and Coke Company, deprived the river of oxygen and inoculated it with cholera. But water companies continued to draw drinking water from the Thames. Outbreaks of cholera and typhoid killed tens of thousands of Londoners and (an event politically more effective) MPs were sickened by a dreadful stink from the river in 1858 as it flowed past the Houses of Parliament.

The familiar chain-reaction began: a Metropolitan Commission of Sewers, renewed six times between 1847 and 1864; Bills debated in Parliament; and eventually two huge sewers, one north and one south of the river, to export the pollution into the estuary, to the jurisdiction of Kent and Essex.

This is but one episode in the long and for a sanitary engineer, exciting - history of the Thames. The river deteriorated again and became a disgrace by 1950 . More committees, more recommendations, more wrangling between authorities as to who was to pay and who was to have authority; and a successful solution to the problem, culminating in press reports of salmon caught in 1974 and, in 1978, 53 species of fish recorded at the intake at West Thurrock power station.

All this, in a vague way, is common knowledge. But only in a vague way. The detailed story of the technological problems, the biological research, the conflicts of interest between those who wanted to be able to drink Thames water and those who wanted to discharge wastes
The Restoration of the Tidal Thames. By Leslie B. Wood. Pp.202. ISBN 0-85274-447-1. (Adam Hilger, Bristol/Heyden: 1982.) £22.50, $\$ 49.50$.

into it, the administrative complexities in the management of a river exploited at one time by 182 separate sewage, gas and petrochemical works, distilleries and paper mills - this story of the Thames has not yet been fully told. But Leslie Wood has given us, in this brief book, the best introduction to the saga that has yet been written. The book is packed with facts, tables, graphs, plans of sewage works and photographs of some of the men whose expertise and persistence have made the restoration of the Thames one of the great success stories in the politics of the environment.

The author begins with a chapter on the history of the river before 1800 , including the fascinating example of what I suppose (to be topical) might be called "punctuated social evolution": the consolidating legislation known as the Bill of Sewers, passed in 1531, and which remained on the statute book, unaltered for 300 years, surviving the industrial revolution. He then takes us through the deterioration of the river from 1800 to 1850 , quoting in full Faraday's famous letter to The Times, recording his observation that bits of paper dropped into the Thames were invisible "before they had sunk an inch below the surface". He quotes, too (though one

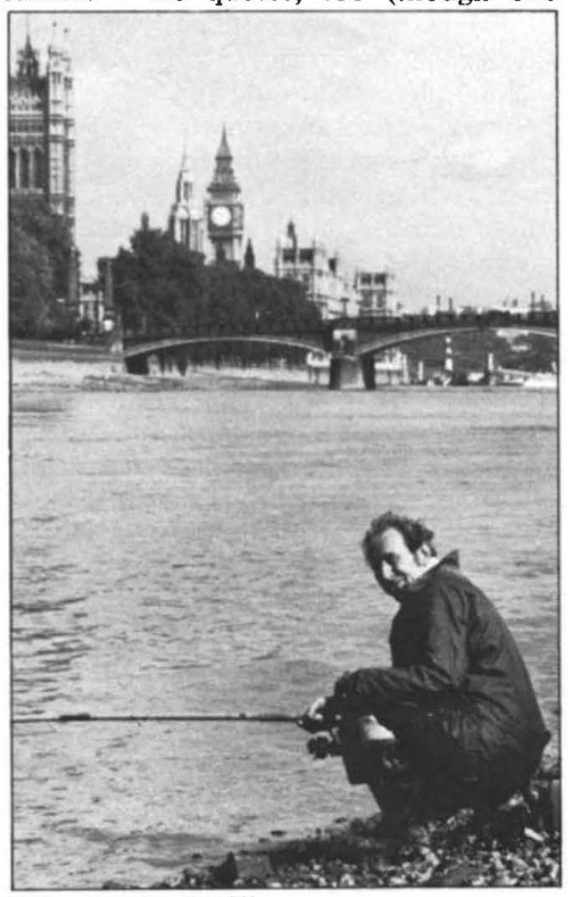

"How clean is a river?" wishes it were in more detail), John Snow's critical observation, with a "control": a record of 71 deaths per 10,000 inhabitants in Southwark, which drew its drinking water from the tidal Thames and, in the same cholera epidemic, only 5 deaths per 10,000 in Lambeth, which drew its drinking water from the Thames too, but above Teddington Weir.

Leslie Wood was an officer employed by the authorities responsible for the management of the tidal Thames and his book is, in a way, a token of appreciation of his colleagues' work. So his main interest is, naturally, not so much in the causes of deterioration but in the measures for restoration. He writes with first-hand knowledge of the strategy being pursued by the Thames Water Authority and he has important things to say - not only for the management of the Thames but about policy for all rivers that run through industrial cities - on the controversial issue of pollution budgets.

Back in 1836 a select committee of Parliament considered a plan for "Rescuing the River Thames from Every Species of Pollution". The managers of the Thames have more modest aims now. Their job is to reconcile many uses of the river, not just to restore it to some Arcadian vision of pristine purity (which in any case it did not have even in the fourteenth century). So instead of "rescuing" the Thames from "Every Species of Pollution" the authority determines what levels of pollution will on one hand enable industry to flourish on the river bank, and on the other hand ensure that the pollutants will be so diluted that they will not harm fish or create a nuisance in any other way. Of particular interest, therefore, is a table on p. 169 of the book, setting out consent conditions for the discharge of trade effluents, including such emotive substances as cyanide, chlorine, formaldehyde, cadmium and lead. How wise, not to pretend that these substances could be totally eliminated, but to set conditions for their release which can reasonably be complied with.

To the question: "How clean is a river?" the scientist can give an answer. But the question: "Is the river clean enough?" cannot be answered by science alone. It is a political question. Leslie Wood's book is a timely reminder that environmental policy is all about the word "enough".

Lord Ashby is a Fellow of Clare College Cambridge. He is joint author with Mary Anderson of The Politics of Clean Air, published by the Clarendon Press in 1981. 